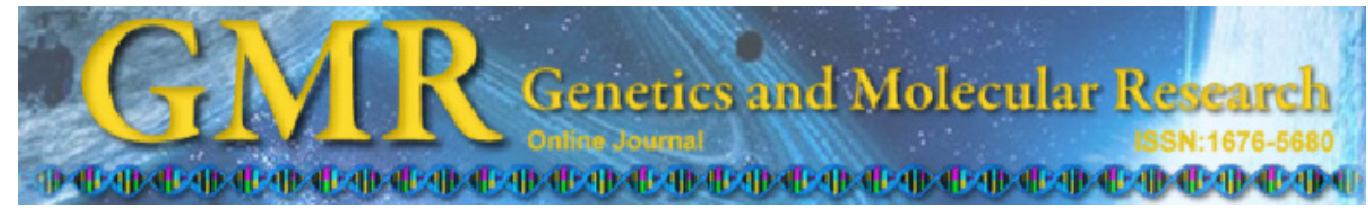

\title{
Association of serum sex steroid levels and bone mineral density with CYP17 and CYP19 gene polymorphisms in postmenopausal women in Turkey
}

\author{
M.B. Yilmaz ${ }^{1}$, A. Pazarbasi ${ }^{1}$, A.I. Guzel ${ }^{1}$, S. Kocaturk-Sel ${ }^{1}$, H. Kasap ${ }^{1}$, \\ M. Kasap ${ }^{1}$, I.F. Urunsak ${ }^{2}$, S. Basaran ${ }^{3}$, D. Alptekin ${ }^{1}$ and O. Demirhan ${ }^{1}$ \\ ${ }^{1}$ Department of Medical Biology and Genetics, Faculty of Medicine, \\ University of Cukurova, Adana, Turkey \\ ${ }^{2}$ Department of Obstetrics and Gynecology, Faculty of Medicine, \\ University of Cukurova, Adana, Turkey \\ ${ }^{3}$ Department of Physical Therapy and Rehabilitation, \\ Faculty of Medicine, University of Cukurova, Adana, Turkey \\ Corresponding author: M.B. Yilmaz \\ E-mail: mbyilmaz@cu.edu.tr
}

Genet. Mol. Res. 10 (3): 1999-2008 (2011)

Received December 9, 2010

Accepted July 25, 2011

Published September 9, 2011

DOI http://dx.doi.org/10.4238/vol10-3gmr1204

\begin{abstract}
Many clinical conditions, including osteoporosis, are associated with serum levels of sex steroids. Enzymes that regulate ratelimiting steps of steroidogenic pathways, such as CYP17 and CYP19, are also regarded as significant factors that may cause the development of these conditions. We investigated the association of two common polymorphisms, in the promoter region ( $\mathrm{T} \rightarrow \mathrm{C}$ substitution) of $\mathrm{CYP} 17$ and exon $3(\mathrm{G} \rightarrow \mathrm{A})$ of CYP19, with bone mineral density (BMD) in the lumbar spine and femoral neck and serum androgen/estradiol, in a case-control study of 172 postmenopausal women aged $62.3 \pm 9.6$ years (mean \pm SD). The CYP17 TC genotype was significantly overrepresented in patients compared to controls, and TC genotype neck T-score and lumbar T-score values were significantly higher in patients compared to controls. CYP17
\end{abstract}


TC and TT genotype testosterone and DHEA-SO $\mathrm{SO}_{4}$ levels were lower in patients compared to controls. All three genotypes of CYP19 had almost the same distribution among patients. The CYP19 AG genotype, however, was most frequent among controls. CYP19 lumbar BMD levels were close to each other among the different genotypes; however, AA and AG genotypes were significantly lower in patients. Testosterone and DHEA-SO ${ }_{4}$ levels in the CYP19 GG genotype were higher compared to those of the other genotypes in patients but not in controls. CYP19 GA individuals had lower $\mathrm{E}_{2}$ levels and lower BMD in controls and patients. Femoral neck BMD and lumbar T-score were also diminished with GA transition. In conclusion, CYP17 and CYP19 gene polymorphisms were found to be associated with osteoporosis in postmenopausal women in Turkey.

Key words: BMD; CYP17; CYP19; Estradiol; Osteoporosis; Polymorphism

\section{INTRODUCTION}

Osteoporosis, a common disease characterized by a generalized reduction in bone mineral density (BMD), disruption of bone architecture and increased fracture risk, is a very important public health problem (Sipos et al., 2009; Compston, 2010). Bone mass peaks between ages 30 and 40 and then declines. There is an initial fast bone loss of $3 \%$ per year for the first few years followed by a slower $1 \%$ loss of BMD per annum. This decrease can be accelerated by such factors as menopause and insufficient dietary calcium. It has been estimated that approximately $50 \%$ of all women will have osteoporosis by the age of 80 , although only a small proportion of these individuals will suffer an osteoporosis-related fracture (Riggs et al., 2002; Waltman et al., 2008; Rabaglio et al., 2009).

Sex steroids are important physiologic regulators of bone mass (Riggs et al., 2002). In this regard, genes regulating sex steroid production and metabolism are possible candidates leading to osteoporosis. Therefore, genetic polymorphisms seen in these genes are likely to affect osteoporosis susceptibility in an individual (Eriksson et al., 2009; Sipos et al., 2009). Osteoporosis has a multi-factorial inheritance pattern. In rare instances, however, osteoporosis is inherited in a simple Mendelian manner. Examples of this include osteogenesis imperfecta and osteoporosis associated with inactivating mutations in the aromatase gene and estrogen receptor gene (Ralston, 2003; Carbonell et al., 2005). Estrogen is essential for normal closure of the growth plates in both genders; thus, estrogen resistance and aromatase deficiency in men are associated with delayed bone age and tall stature, despite normal or high circulating concentrations of testosterone (Simpson, 2000).

The adrenal and gonadal steroid hormones are produced in a multistep process that involves the participation of six P450 cytochromes: CYP11A1, CYP17, CYP21, CYP11B1, CYP11B2, and CYP19. Of these enzymes, CYP17 and CYP19 catalyze the rate-limiting steps of estrogen biosynthesis (Nelson and Bulun, 2001; Bulun et al., 2005). Estrogen biosynthesis is dependent on the facilitation of the entry of cholesterol into mitochondria followed by six enzymatic steps. Aromatase is the key enzyme and catalyzes the final step, i.e., the conversion of $\mathrm{C}_{19}$ steroids to the biologically active estrogen, estradiol $\left(\mathrm{E}_{2}\right)$. A single gene (Cyp19a1) encodes aromatase, the inhibition of which effectively eliminates estrogen production in the entire 
body. Human aromatase gene is located on 15q11-q12, spanning a 130-kb region. Expression of the aromatase gene is regulated by the tissue-specific activation of a number of promoters via alternative splicing. Aromatase mRNA species contain promoter-specific 5'-UTRs. The coding region and encoded protein, however, are identical, regardless of the promoter used (Nelson and Bulun, 2001; Bulun et al., 2005). The occurrence of osteoporosis is closely related to serum estradiol level. Therefore, any irregularities in aromatase gene, such as polymorphisms, will in turn result in changes in estradiol concentrations in both genders (Khosla, 2010). Indeed, a tetranucleotide simple tandem repeat polymorphism in intron 4 of the CYP19 gene has been related to both female and male osteoporosis (Siegelmann-Danieli and Buetow, 1999). Furthermore, a $\mathrm{G}$ to A substitution polymorphism in exon 3 is thought to be related to serum estradiol concentrations and BMD in postmenopausal women (Masi et al., 2001; Somner et al., 2004).

In this context, the other rate-limiting enzyme, CYP17, whose gene is located on 10q 24-q25, spanning a 1870-bp region, is also important in estrogen formation. CYP17, encoded by the CYP17 gene, catalyzes the conversion of progesterone and pregnenolone into precursors of potent androgens (Sharp et al., 2004). CYP17 is predominantly expressed in the adrenal gland, testicular Leydig cells, and ovarian theca cells. In the 5' promoter region of the CYP17 gene, a $\mathrm{T}$ (A1 allele) to C substitution (A2 allele) has been hypothesized to alter CYP17 gene expression (Zmuda et al., 2001). Loss of function mutations in the CYP17 gene results in reduced growth and osteoporosis. A common polymorphic variant in the CYP17 gene has recently been shown to be associated with femoral size and biologically available testosterone concentration in men (Ye and Parry, 2002; Sharp et al., 2004).

In the present study, we investigated the association of CYP17 and CYP19 polymorphisms with BMD in a group of postmenopausal women with osteoporosis. This is the first study in Turkey examining the possible effects of these polymorphisms on BMD.

\section{MATERIAL AND METHODS}

\section{Subjects}

One hundred and thirty-six postmenopausal women with osteoporosis and 36 postmenopausal women without osteoporosis (control group) were recruited for our study. Ages of the participants varied between 46 and 80 years. This study was approved by the local Research Ethics Committee of Cukurova University School of Medicine and informed consent was obtained from each participant.

One hundred and thirty-six women with osteoporosis, defined by a T-score of -2.5 or less at the lumbar spine and/or hip sites, using the NHANES 111 study reference range, were consecutively recruited during their attendance at the Osteoporosis Screening Unit at Cukurova Univesity Hospital between April 2006 and October 2009. Individuals with secondary causes of osteoporosis or bone loss, such as inflammatory diseases (e.g., rheumatoid arthritis), malignancy, chronic renal failure, immobilization, hyperparathyroidism, thyrotoxicosis, and corticosteroid use, were excluded.

For all study subjects, clinical information including age at menarche and menopause, years since menopause, history of fractures, intake of dairy products, alcohol intake, smoking habits, degree of exercise, and family history of osteoporosis were obtained through a questionnaire. Blood was obtained from all study participants for DNA extraction and for the measurement of sex steroids. For the hormone determinations, blood was centrifuged, and the serum samples were stored at $-20^{\circ} \mathrm{C}$ until analysis. 


\section{Bone densitometry and hormone measurement}

BMD of the patients was measured from the lumbar vertebrae and femoral neck using the dual-energy X-ray absorbtiometry (DEXA) method (Norland Bone Densitometer, Medical Systems, Inc.). All subjects underwent DXA screening of lumbar vertebrae 2 to 4 (L2-L4). DXA screenings were performed by the Department of Radiology at the Cukurova University Hospital (GE Healthcare, Lunar Densitometry, Madison, WI, USA) in the anteroposterior position with a precision error of $\pm 1.5 \%$. According to the reference population of the scanner manufacturers, T-scores were obtained for each subject. Subjects were classified as normal (T-score of $>-1.0$ ), osteopenic (T-score of -1 to -2.5 ) or osteoporotic (T-score of $<-2.5$ ), according to the World Health Organization classification. Subjects who were osteopenic or osteoporotic, thus indicating low skeletal BMD, were classified into the "reduced bone density group", and all the other subjects were classified into the "normal group". Circulating blood levels of testosterone-estradiol and DHEAS were measured using Immunotec immunoradiometric and radioimmunoassay kits, respectively. The testosterone assays had a sensitivity of $0.069 \mathrm{nM}(0.02 \mathrm{ng} / \mathrm{mL})$.

\section{DNA extraction and analysis}

Genomic DNA was extracted from peripheral blood leukocytes using a salting-out extraction method. A 459-bp fragment of genomic DNA containing the T to C substitution at -34 bp in the CYP17 gene was amplified by polymerase chain reaction (PCR) as previously described by Somner et al. (2004) with minor modifications. PCR was carried out in a $25-\mu \mathrm{L}$ reaction mixture containing $200 \mathrm{ng}$ genomic DNA, $2.0 \mathrm{mM}$ magnesium chloride, $250 \mu \mathrm{M}$ dNTPs, 0.5 $\mu \mathrm{M}$ of each primer, and $0.5 \mathrm{U}$ Taq DNA polymerase. Primer sequences were as follows: forward, 5'-CATTCGCACTCTGGAGTC-3', and reverse, 5'-AGGCTCTTGGGGTACTTG-3'. After an initial denaturation at $95^{\circ} \mathrm{C}$ for $3 \mathrm{~min}, 35$ cycles of amplification with denaturation at $95^{\circ} \mathrm{C}$ for 30 $\mathrm{s}$, annealing at $58^{\circ} \mathrm{C}$ for $45 \mathrm{~s}$, and extension at $72^{\circ} \mathrm{C}$ for $45 \mathrm{~s}$ were performed, followed by a final extension step of $7 \mathrm{~min}$ at $72^{\circ} \mathrm{C}$. The $\mathrm{T}$ to $\mathrm{C}$ substitution creates a recognition site for the restriction enzyme MspA1. After amplification, all samples were digested overnight with $5 \mathrm{U}$ MspA1. In subjects with the $\mathrm{C}$ allele, two smaller fragments of 335 and $124 \mathrm{bp}$ were obtained, as shown in Figure 1. For determination of the $\mathrm{G} \rightarrow \mathrm{A}$ substitution at position $\mathrm{Va}^{80}{ }^{80}$ in CYP19, a 188-bp PCR product was generated. PCR was carried out in a $25-\mu$ Lreaction mixture containing $200 \mathrm{ng}$ genomic DNA, $2.0 \mathrm{mM}$ magnesium chloride, $250 \mu \mathrm{M}$ dNTPs, $0.5 \mu \mathrm{M}$ of each primer, and $0.5 \mathrm{U}$ Taq DNA polymerase. Primer sequences were as follows: forward, 5'-AGTAACACAGAACAGTTGCA-3', reverse, 5'-TCCAGACTCGCATGAATTCTCC $\underline{G T A-3 ' . ~ A ~ m i s m a t c h ~(~} \underline{G}$ instead of A) was introduced in the reverse primer to create a restriction site for the enzyme $R s a 1$. The presence of the $\mathrm{G}$ variant in CYP19 resulted in digestion of the 188-bp amplicon to two smaller fragments of 164 and $24 \mathrm{bp}$. The fragments were separated on a 3\% agarose gel containing ethidium bromide and viewed by UV illumination. Only one 188-bp fragment was seen in subjects with the AA genotype. In subjects with the GA genotype, two bands of 188 and 164 bp were seen, whereas in those subjects homozygous for the G variant (GG), only one 164-bp PCR fragment was seen. All PCR amplifications were carried out using a DNA thermocycler (Mastercycler, Eppendorf, Hamburg, Germany). After an initial denaturation at $95^{\circ} \mathrm{C}$ for $3 \mathrm{~min}, 35$ cycles of amplification with denaturation at $95^{\circ} \mathrm{C}$ for $30 \mathrm{~s}$, annealing at $57^{\circ} \mathrm{C}$ for $1 \mathrm{~min}$, and extension at $72^{\circ} \mathrm{C}$ for 45 $\mathrm{s}$ were performed, followed by a final extension step of $7 \mathrm{~min}$ at $72^{\circ} \mathrm{C}$. The PCR product was 
digested overnight with $5 \mathrm{U}$ Rsa1. PCRs were performed in triplicate to check the reproducibility of the experiments. A representative experiment showing the different genotypes of CYP19 and CYP17 are shown in Figure 1A and B, respectively.
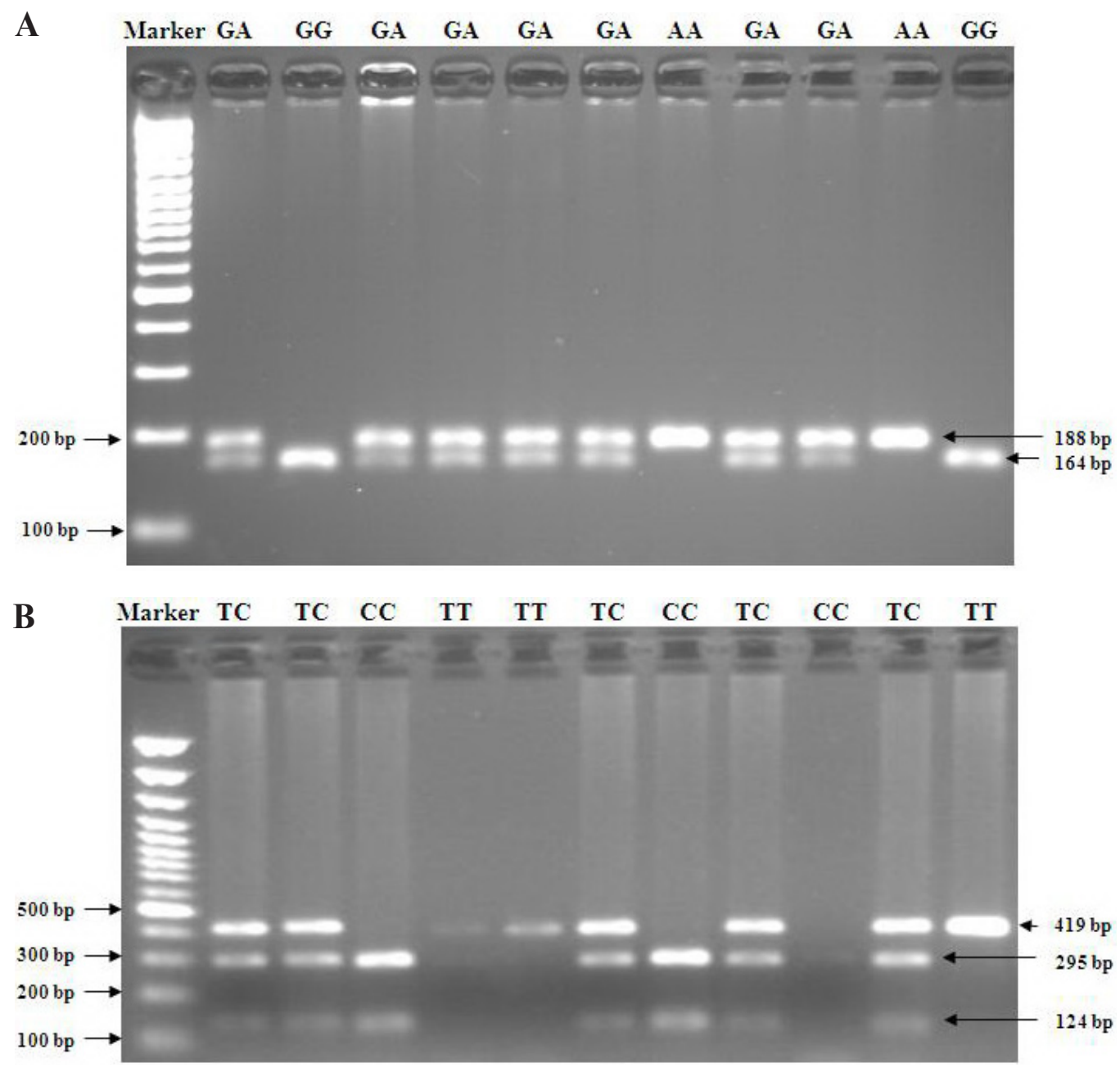

Figure 1. A. CYP19 amplification-RSA1 digestion. B. CYP17 amplification-MSPA1 digestion.

\section{Statistical analysis}

Statistical analyses for comparing individual allele and genotype frequencies were carried out using the chi-square test (two-sided asymptotic P values) with the SPSS ver. 11.0 (SPSS, Chicago, IL, USA) software. P $<0.05$ was considered to be statistically significant. ANOVA was used to identify any potential association between phenotypes and genotypes. The association between genetic findings and osteoporosis was evaluated by multiple regression analysis. 


\section{RESULTS}

Clinical and biochemical findings of the whole study population are shown in Table 1. There was a significant difference in estradiol and testosterone levels between controls and patients. We found, however, that the CYP17 TC genotype was overrepresented in patients compared to controls, which was statistically significant (Table 2). CYP17 TC genotype frequency, femoral neck T-score and lumbar T-score were also higher in patients compared to controls (Table 3). We did not observe the CYP17 CC genotype among controls; however, $18 \%$ of the patients had this genotype. We also did not observe any statistically significant difference between CYP17 genotypes in terms of lumbar BMD, femoral neck BMD, neck T-score, and lumbar T-score (Table 3). In CYP17 TC and TT genotypes, testosterone and DHEA-SO ${ }_{4}$ levels were lower in patients compared to controls; $\mathrm{E}_{2}$ levels of controls, however, were not statistically different from patients (Table 4).

\begin{tabular}{|c|c|c|c|c|}
\hline Parameter measured & Mean and median & Controls & Patients & $\mathrm{P}$ \\
\hline \multirow[t]{2}{*}{ Height $(\mathrm{cm})$} & Mean & $159.53 \pm 5.16$ & $156.06 \pm 5.94$ & 0.03 \\
\hline & Median (Min-Max) & $160(149-172)$ & $156(130-165)$ & \\
\hline \multirow{2}{*}{ Weight (kg) } & Mean & $76.62 \pm 13.70$ & $63.29 \pm 11.77$ & 0.01 \\
\hline & Median (Min-Max) & $74.5(46-110)$ & $62(45-90)$ & \\
\hline \multirow{2}{*}{ Body mass index $\left(\mathrm{kg} / \mathrm{m}^{2}\right)$} & Mean & $30.20 \pm 5.32$ & $26.01 \pm 4.87$ & 0.005 \\
\hline & Median (Min-Max) & $29.2(18-43)$ & $25.6(16.5-38.7)$ & \\
\hline \multirow{2}{*}{ Age at presentation (years) } & Mean & $58.88 \pm 8.72$ & $63.32 \pm 9.91$ & 0.006 \\
\hline & Median (Min-Max) & $56.60(47-90)$ & $61(44-84)$ & \\
\hline \multirow{2}{*}{ Age at menarche (years) } & Mean & $13 \pm 0.92$ & $13.49 \pm 1.29$ & 0.03 \\
\hline & Median (Min-Max) & $13(11-15)$ & $13(11-15)$ & \\
\hline \multirow{2}{*}{ Age at menopause (years) } & Mean & $49.03 \pm 3.80$ & $45.79 \pm 4.88$ & 0.001 \\
\hline & Median (Min-Max) & $48.5(40-55)$ & $46(35-55)$ & \\
\hline \multirow{2}{*}{ Years since menopause (years) } & Mean & $9.85 \pm 1.70$ & $17.52 \pm 10.85$ & 0.003 \\
\hline & Median (Min-Max) & $7(1-42)$ & $15(1-40)$ & \\
\hline \multirow{2}{*}{ Calcium (mg/dL) } & Mean & $9.39 \pm 0.37$ & $9.74 \pm 0.42$ & 0.00 \\
\hline & Median (Min-Max) & $9.3(8.8-10.4)$ & $9.8(8.9-10.6)$ & \\
\hline \multirow{2}{*}{ Phosphate (mg/dL) } & Mean & $3.79 \pm 0.57$ & $3.58 \pm 0.52$ & 0.17 \\
\hline & Median (Min-Max) & $3.7(2.8-5.3)$ & $3.6(2.3-4.6)$ & \\
\hline \multirow{2}{*}{$\operatorname{ALP}(\mathrm{U} / \mathrm{L})$} & Mean & $195.41 \pm 40.57$ & $180.17 \pm 72.72$ & 0.02 \\
\hline & Median (Min-Max) & $189.5(115-310)$ & $166(73-496)$ & \\
\hline \multirow{2}{*}{ Osteocalcin (ng/mL) } & Mean & $19.90 \pm 6.32$ & $21.05 \pm 16.56$ & 0.68 \\
\hline & Median (Min-Max) & $18.6(7.3-41.49)$ & $18.8(6.6-136.9)$ & \\
\hline \multirow[t]{2}{*}{$\beta$-crosslaps (ng/mL) } & Mean & $0.25 \pm 0.12$ & $0.29 \pm 0.21$ & 0.84 \\
\hline & Median (Min-Max) & $0.24(0.07-0.65)$ & $0.23(0.03-0.96)$ & \\
\hline \multirow[t]{2}{*}{ Vit D3 } & Mean & $19.68 \pm 11.69$ & $35.01 \pm 18.80$ & 0.00 \\
\hline & Median (Min-Max) & $19(4-49)$ & $32(5-98)$ & \\
\hline \multirow[t]{2}{*}{ PTH (pg/mL) } & Mean & $44.88 \pm 14.19$ & $59.39 \pm 24.08$ & 0.002 \\
\hline & Median (Min-Max) & $44(18.8-79.2)$ & $57.5(20.4-164.7)$ & \\
\hline \multirow[t]{2}{*}{ Estradiol } & Mean & $13.44 \pm 12.60$ & $16.59 \pm 9.04$ & 0.01 \\
\hline & Median (Min-Max) & $12.06(5-68.17)$ & $16.56(4.74-56.31)$ & \\
\hline \multirow[t]{2}{*}{ Testosterone } & Mean & $0.20 \pm 0.31$ & $0.2477 \pm 0.21$ & 0.01 \\
\hline & Median (Min-Max) & $0.12(0.02-1.92)$ & $0.1970(0.02-1.71)$ & \\
\hline \multirow[t]{2}{*}{ DHEA-SO ${ }_{4}$} & Mean & $83.66 \pm 47.40$ & $79.91 \pm 49.62$ & 0.85 \\
\hline & Median (Min-Max) & $69.21(22.60-186)$ & $67.64(7.05-229.80)$ & \\
\hline \multirow[t]{2}{*}{ Lumbar spine BMD } & Mean & $0.93721 \pm 0.081197$ & $0.72900 \pm 0.114438$ & 0.001 \\
\hline & Median (Min-Max) & $0.93050(0.787-1.14)$ & $0.74000(0.400-1.07)$ & \\
\hline \multirow[t]{2}{*}{ Femoral neck BMD } & Mean & $0.85997 \pm 0.097459$ & $0.66412 \pm 0.097047$ & 0.004 \\
\hline & Median (Min-Max) & $0.87050(0.650-1.0)$ & $0.66700(0.390-0.860)$ & \\
\hline \multirow[t]{2}{*}{ Lumbar spine T-score } & Mean & $-0.9706 \pm 0.73465$ & $-2.9056 \pm 1.05842$ & 0.004 \\
\hline & Median (Min-Max) & $-1.0500(-2.0-0.90)$ & $-2.8000(-7.0-20)$ & \\
\hline \multirow[t]{2}{*}{ Femoral neck T-score } & Mean & $-0.6697 \pm 0.80155$ & $-2.0143 \pm 0.84485$ & 0.003 \\
\hline & Median (Min-Max) & $-0.8000(-2.0-0.50)$ & $-2.1000(-4.0-0.10)$ & \\
\hline
\end{tabular}

$\mathrm{ALP}=$ alkaline phosphatase; $\mathrm{PTH}=$ parathyroid hormone; $\mathrm{DHEA}-\mathrm{SO}_{4}=$ dehydroepiandrosterone sulfate; $\mathrm{BMD}=$ bone mineral density. 


\begin{tabular}{|c|c|c|}
\hline & Controls $(\mathrm{N}=36)$ & Patients $(\mathrm{N}=136)$ \\
\hline \multicolumn{3}{|c|}{$\overline{\text { CYP17 }}$} \\
\hline TT & $13(36 \%)$ & $53(38 \%)$ \\
\hline $\mathrm{TC}$ & $23(64 \%)$ & $61(44 \%)$ \\
\hline $\mathrm{CC}$ & $0(0 \%)$ & $22(18 \%)$ \\
\hline \multicolumn{3}{|c|}{ CYP19 } \\
\hline AA & $10(27 \%)$ & $57(41 \%)$ \\
\hline $\mathrm{AG}$ & $23(63 \%)$ & $34(25 \%)$ \\
\hline GG & $3(10 \%)$ & $45(34 \%)$ \\
\hline
\end{tabular}

Table 3. CYP17 genotype values in lumbar and femoral neck BMD and lumbar and femoral neck T-score of controls and patients.

\begin{tabular}{|c|c|c|c|c|c|c|}
\hline & \multicolumn{2}{|c|}{ TT } & \multicolumn{2}{|c|}{$\mathrm{TC}$} & \multicolumn{2}{|c|}{$\mathrm{CC}$} \\
\hline & Controls & Patients & Controls & Patients & Controls & Patients \\
\hline Lumbar BMD & $0.95627 \pm 0.073$ & $0.73633 \pm 0,122$ & $0.92809 \pm 0,084$ & $0.71766 \pm 0,118$ & - & $0.74356 \pm 0.092$ \\
\hline Femoral neck BMD & $0.86045 \pm 0.114$ & $0.65930 \pm 0.103$ & $0.85974 \pm 0.911$ & $0.65766 \pm 0.118$ & - & $0.68763 \pm 0.069$ \\
\hline Lumbar T-score & $-0.7636 \pm 0.6$ & $-2.8767 \pm 1.990$ & $-1.0696 \pm 0.780$ & $-2.9945 \pm 1.052$ & - & $-2.7431 \pm 0.837$ \\
\hline Neck T-score & $-0.7018 \pm 0.903$ & $-2.0533 \pm 0.772$ & $-0.6543 \pm 0.769$ & $-2.0058 \pm 0.970$ & - & $-1.9688 \pm 0.667$ \\
\hline
\end{tabular}

Table 4. Serum androgen and estradiol concentrations according to CYP17 genotypes in controls and patients.

\begin{tabular}{|c|c|c|c|c|c|c|}
\hline & \multicolumn{2}{|c|}{$\mathrm{TT}$} & \multicolumn{2}{|c|}{$\mathrm{TC}$} & \multicolumn{2}{|r|}{$\mathrm{CC}$} \\
\hline & Controls & Patients & Controls & Patients & Controls & Patients \\
\hline Testosterone & $0.3055 \pm 0.491$ & $0.253 \pm 0.261$ & $0.1500 \pm 0.133$ & $0.2360 \pm 0.177$ & - & $0.2661 \pm 0.153$ \\
\hline & $16.34 \pm 19.414$ & $15.615 \pm 9.383$ & $11.972 \pm 6.801$ & $16.558 \pm 8.747$ & - & $18.973 \pm 8.981$ \\
\hline DHEA-SO & $72.66 \pm 42.663$ & $71.30 \pm 45.517$ & $96.62 \pm 53.428$ & $84.511 \pm 47.542$ & - & $87.93 \pm 62.883$ \\
\hline
\end{tabular}

$\mathrm{E}_{2}=$ estradiol; DHEA-SO $\mathrm{SO}_{4}=$ dehydroepiandrosterone sulfate.

As for CYP19, all genotypes showed almost the same distribution among patients; however, the CYP19 AG genotype was the most frequent among controls (Table 2). CYP19 lumbar BMD levels were close to each other in different genotypes; however, AA and AG genotypes were significantly less frequent in patients. Femoral neck BMD and lumbar T-scores were also diminished with GA transition (Table 5). $\mathrm{E}_{2}$ levels in CYP19 AA and AG genotypes were lower in patients compared to controls. Testosterone and DHEA-SO ${ }_{4}$ levels in the CYP19 GG genotype were higher compared to other genotypes in patients but not in controls (Table 6). BMD, hormonal levels and genotypes showed a significant correlation among each other.

Table 5. CYP19 genotype values in lumbar and femoral neck BMD and lumbar and femoral neck T-score of controls and patients.

\begin{tabular}{|c|c|c|c|c|c|c|}
\hline & \multicolumn{2}{|c|}{ AA } & \multicolumn{2}{|c|}{ AG } & \multicolumn{2}{|c|}{ GG } \\
\hline & Controls & Patients & Controls & Patients & Controls & Patients \\
\hline Lumbar BMD & $0.9558 \pm 0.098$ & $0.74124 \pm 0.09$ & $0.9376 \pm 0.075$ & $0.6295 \pm 0.154$ & $0.8856 \pm 0.084$ & $1.710 \pm 0.121$ \\
\hline Femoral neck BMD & $0.868 \pm 0.813$ & $0.6566 \pm 0.091$ & $0.8546 \pm 0.104$ & $0.5957 \pm 0.134$ & $-1.199 \pm 0.108$ & $0.678 \pm 0.097$ \\
\hline Lumbar T-score & $-0.825 \pm 0.901$ & $-2.816 \pm 0.871$ & $-0.956 \pm 0.674$ & $-3.774 \pm 1.367$ & $-1.466 \pm 0.776$ & $-2.90 \pm 1.176$ \\
\hline Neck T-score & $-0.587 \pm 0.683$ & $-2.054 \pm 0.828$ & $-0.720 \pm 0.855$ & $-2.425 \pm 1.004$ & $-0.500 \pm 0.906$ & $-1.93 \pm 0.853$ \\
\hline
\end{tabular}


Table 6. Serum androgen and estradiol concentrations according to CYP19 genotypes in controls and patients.

\begin{tabular}{|c|c|c|c|c|c|c|}
\hline & \multicolumn{2}{|c|}{$\mathrm{AA}$} & \multicolumn{2}{|c|}{$\mathrm{AG}$} & \multicolumn{2}{|c|}{ GG } \\
\hline & Controls & Patients & Controls & Patients & Controls & Patients \\
\hline Testosterone & $0.150 \pm 0.07$ & $0.2276 \pm 0.238$ & $0.228 \pm 0.40$ & $0.264 \pm 0.245$ & $0.335 \pm 0.018$ & $0.260 \pm 0.142$ \\
\hline $\mathrm{E}_{2}$ & $11.32 \pm 7.59$ & $14.982 \pm 9.131$ & $15.58 \pm 15.45$ & $14.812 \pm 8.097$ & $18.885 \pm 7.347$ & $19.982 \pm 8.832$ \\
\hline DHEA-SO & $95.11 \pm 37.31$ & $76.12 \pm 42.72$ & $74.93 \pm 47.82$ & $96.375 \pm 52.578$ & $174.7 \pm 15.98$ & $72.285 \pm 53.599$ \\
\hline
\end{tabular}

$\mathrm{E}_{2}=$ estradiol; DHEA- $\mathrm{SO}_{4}=$ dehydroepiandrosterone sulfate.

\section{DISCUSSION}

Estrogens and androgens have a significant impact on bone development (Sipos et al., 2009). In this regard, enzymes that function in steroidogenesis pathways are substantial candidates for androgen- and estrogen-associated disorders such as osteoporosis (Riggs et al., 2002; Khosla, 2010). In these pathways, CYP17 and CYP19 enzymes, which catalyze the rate-limiting steps, play critical roles in estrogen and androgen synthesis (Sharp et al., 2004; Bulun et al., 2005). Of these two enzymes, CYP17 T to C polymorphic variant is implicated in osteoporotic predisposition. Most studies, however, could not establish a relationship between CYP17 TC polymorphism and circulating estrogen-androgen levels (Berstein et al., 2002; Feigelson et al., 2002; Kado et al., 2002; Ye and Parry, 2002; Somner et al., 2004). We also did not observe a statistically significant association between CYP17 TC polymorphism and sex steroid levels; however, there was a tendency of higher testosterone levels in osteoporotic patients compared to controls in the CYP17 TC genotype. Interestingly, we could not detect the CYP17 CC genotype in the control group. The CYP17 CC genotype was also found to show a very low frequency, probably because it is more pronounced in osteoporotic phenotypes as suggested by Somner et al. (2004). CYP17 polymorphism could also play significant roles in testosterone synthesis, which functions in bone physiology, and therefore, it is possible that CYP17 is a strong candidate that functions in bone metabolism even though this gene has gender-specific effects on steroid metabolism (Zmuda et al., 2001; Ye and Parry, 2002; Sharp et al., 2004).

Some studies have postulated that polymorphisms in CYP19, a rate-limiting enzyme for biologically active estradiol synthesis, are also important for osteoporotic pathology (Bulun et al., 2005; Sipos et al., 2009). In contrast to some previous studies, we found that both CYP19 AA and GG but not AG genotypes are associated with increased risk of osteoporosis (Langdahl et al., 2000; Somner et al., 2004; Tofteng et al., 2004; Riancho et al., 2005). Interestingly, lumbar BMD values in patients were significantly increased compared to controls in CYP19 GG genotypes, which also had the highest increase in prevalence in patients compared to other genotypes. As in previous research on this issue, we could not detect a direct association between CYP17-CYP19 polymorphisms and hormonal levels possibly due to the medication taken by osteroporotic patients (Langdahl et al., 2000; Gennari et al., 2002; Riancho et al., 2005; Lorentzon et al., 2006; Waltman et al., 2008).

At the molecular level, it is unclear how CYP17 and CYP19 SNPs alter their own transcriptional regulation. It is possible that the CYP17 $\mathrm{T} \rightarrow \mathrm{C}$ substitution bears a different binding site for transcription factors, which in turn upregulate or downregulate its expression. Deletion construct transfection and ChIP assays with human cell lines may be 
helpful to delineate their function in the hormonal regulation. Likewise, the CYP19 A $\rightarrow \mathrm{G}$ substitution could also be important in its own transcriptional regulation.

In summary, our findings and previous ones suggest that both CYP17 and CYP19 polymorphisms could be related to osteoporosis in the Cukurova region in Turkey. Moreover, of these polymorphisms, CYP17 TC polymorphism is associated with lumbar BMD in postmenopausal women. CYP19 GA polymorphism, on the other hand, is associated with estradiol synthesis, which in turn affects the prevalence of osteoporosis. In conclusion, both CYP17 and CYP19 are useful markers for the occurrence and progression of osteoporosis.

\section{REFERENCES}

Berstein LM, Imyanitov EN, Gamajunova VB, Kovalevskij AJ, et al. (2002). CYP17 genetic polymorphism in endometrial cancer: are only steroids involved? Cancer Lett. 180: 47-53.

Bulun SE, Lin Z, Imir G, Amin S, et al. (2005). Regulation of aromatase expression in estrogen-responsive breast and uterine disease: from bench to treatment. Pharmacol. Rev. 57: 359-383.

Carbonell SS, Masi L, Marini F, Del Monte F, et al. (2005). Genetics and pharmacogenetics of osteoporosis. J. Endocrinol. Invest. 28: 2-7.

Compston J (2010). Osteoporosis: social and economic impact. Radiol. Clin. North Am. 48: 477-482.

Eriksson AL, Lorentzon M, Vandenput L, Labrie F, et al. (2009). Genetic variations in sex steroid-related genes as predictors of serum estrogen levels in men. J. Clin. Endocrinol. Metab. 94: 1033-1041.

Feigelson HS, McKean-Cowdin R and Henderson BE (2002). Concerning the CYP17 MspA1 polymorphism and breast cancer risk: a meta-analysis. Mutagenesis 17: 445-446.

Gennari L, Becherini L, Falchetti A, Masi L, et al. (2002). Genetics of osteoporosis: role of steroid hormone receptor gene polymorphisms. J. Steroid Biochem. Mol. Biol. 81: 1-24.

Kado N, Kitawaki J, Obayashi H, Ishihara H, et al. (2002). Association of the CYP17 gene and CYP19 gene polymorphisms with risk of endometriosis in Japanese women. Hum. Reprod. 17: 897-902.

Khosla S (2010). Update on estrogens and the skeleton. J. Clin. Endocrinol. Metab. 95: 3569-3577.

Langdahl BL, Lokke E, Carstens M, Stenkjaer LL, et al. (2000). A TA repeat polymorphism in the estrogen receptor gene is associated with osteoporotic fractures but polymorphisms in the first exon and intron are not. J. Bone Miner. Res. 15: 2222-2230.

Lorentzon M, Swanson C, Eriksson AL, Mellstrom D, et al. (2006). Polymorphisms in the aromatase gene predict areal BMD as a result of affected cortical bone size: the GOOD study. J. Bone Miner. Res. 21: 332-339.

Masi L, Becherini L, Gennari L, Amedei A, et al. (2001). Polymorphism of the aromatase gene in postmenopausal Italian women: distribution and correlation with bone mass and fracture risk. J. Clin. Endocrinol. Metab. 86: 2263-2269.

Nelson LR and Bulun SE (2001). Estrogen production and action. J. Am. Acad. Dermatol. 45: S116-S124.

Rabaglio M, Sun Z, Price KN, Castiglione-Gertsch M, et al. (2009). Bone fractures among postmenopausal patients with endocrine-responsive early breast cancer treated with 5 years of letrozole or tamoxifen in the BIG 1-98 trial. Ann. Oncol. 20: 1489-1498.

Ralston SH (2003). Genetic determinants of susceptibility to osteoporosis. Curr. Opin. Pharmacol. 3: 286-290.

Riancho JA, Zarrabeitia MT, Valero C, Sanudo C, et al. (2005). Aromatase gene and osteoporosis: relationship of ten polymorphic loci with bone mineral density. Bone 36: 917-925.

Riggs BL, Khosla S and Melton LJ (2002). Sex steroids and the construction and conservation of the adult skeleton. Endocr. Rev. 23: 279-302.

Sharp L, Cardy AH, Cotton SC and Little J (2004). CYP17 gene polymorphisms: prevalence and associations with hormone levels and related factors. a HuGE review. Am. J. Epidemiol. 160: 729-740.

Siegelmann-Danieli N and Buetow KH (1999). Constitutional genetic variation at the human aromatase gene (Cyp19) and breast cancer risk. Br. J. Cancer 79: 456-463.

Simpson ER (2000). Role of aromatase in sex steroid action. J. Mol. Endocrinol. 25: 149-156.

Sipos W, Pietschmann P, Rauner M, Kerschan-Schindl K, et al. (2009). Pathophysiology of osteoporosis. Wien. Med. Wochenschr. 159: 230-234.

Somner J, McLellan S, Cheung J, Mak YT, et al. (2004). Polymorphisms in the P450 c17 (17-hydroxylase/17,20-Lyase) and P450 c19 (aromatase) genes: association with serum sex steroid concentrations and bone mineral density in postmenopausal women. J. Clin. Endocrinol. Metab. 89: 344-351. 
Tofteng CL, Kindmark A, Brandstrom H, Abrahamsen B, et al. (2004). Polymorphisms in the CYP19 and AR genes relation to bone mass and longitudinal bone changes in postmenopausal women with or without hormone replacement therapy: the Danish osteoporosis prevention study. Calcif. Tissue Int. 74: 25-34.

Waltman NL, Ott CD, Twiss JJ, Gross GJ, et al. (2008). Bone mineral density and bone turnover in postmenopausal women treated for breast cancer. Cancer Nurs. 31: 182-190.

Ye Z and Parry JM (2002). The CYP17 MspA1 polymorphism and breast cancer risk: a meta-analysis. Mutagenesis 17: 119-126.

Zmuda JM, Cauley JA, Kuller LH and Ferrell RE (2001). A common promotor variant in the cytochrome P450c17alpha (CYP17) gene is associated with bioavailability testosterone levels and bone size in men. J. Bone Miner. Res. 16: 911-917. 